\title{
Is Bottom Boundary Layer Mixing Slowly Ventilating Greenland Sea Deep Water?*
}

\author{
MARTIN VISBECK \\ Lamont-Doherty Earth Observatory of Columbia University, Palisades, New York \\ MONIKA RHEIN \\ Institut für Ostseeforschung, Rostock, Germany
}

16 January 1998 and 21 June 1999

\begin{abstract}
Bottom water temperatures in the central Greenland Sea have been increasing for the last two decades. The warming is most likely related to the absence of deep convective mixing, which cools and freshens the deep water. However, recent observations confirm a slow and steady increase of anthropogenic tracers such as chlorofluorocarbons (CFCs). This points to some amount of bottom water "ventilation" in the absence of deep convective mixing and poses a challenge to our understanding of deep water renewal. One explanation for the observed trends in both temperature and CFCs is significant vertical mixing. The basin-averaged diapycnal diffusivity, required to explain both trends, $k_{v, \text { av }} \sim 2-3\left(\times 10^{-3} \mathrm{~m}^{2} \mathrm{~s}^{-1}\right)$, is very unlikely to occur in the interior of the ocean. However, a diffusivity of $k_{v, \text { bbl }} \sim 10^{-2} \mathrm{~m}^{2} \mathrm{~s}^{-1}$ within a $150-\mathrm{m}$ thick bottom boundary layer would be sufficient to explain the deep tracer increase. The implications of a secondary circulation driven by such large boundary layer mixing are discussed.
\end{abstract}

\section{Introduction}

Since the turn of the century several authors have proposed that the central Greenland Sea (Fig. 1) is a site of deep and bottom water formation by open ocean deep convection. However, the absence of direct observational evidence for deep convective mixing raised the possibility that internal double diffusive mixing processes might ventilate the deep and bottom waters (see Carmack and Aagaard 1973; Clarke et al. 1990, and references therein). But the distribution of tracers like tritium, radiocarbon, argon-39, and chlorofluorocarbons contradicted this suggestion. The high levels of these tracers in the deep and bottom waters of the Greenland Sea pointed strongly to processes of convective deepwater renewal involving the surface layer with its high tracer content (Peterson and Rooth 1976; Smethie et al. 1986).

A few years later Rudels et al. (1989) found the first well-mixed temperature and salinity profiles from the surface down to about $2000 \mathrm{~m}$ depth, and Schott et al.

\footnotetext{
* Lamont-Doherty Observatory Contribution Number 5965.
}

Corresponding author address: Dr. Martin Visbeck, Lamont-Doherty Earth Observatory of Columbia University, P.O. Box 1000, 61 Route 9W, Palisades, NY 10964-8000.

E-mail: visbeck@1deo.columbia.edu
(1993) detected significant deep downwelling velocities. This supports the occurrence of deep convective mixing in the Greenland Sea. However, as yet convective bottom water renewal has not been directly observed, despite intense observational efforts.

In addition to dynamical active tracers, such as temperature and salinity, tracers with a strongly varying surface boundary condition can be used to infer the intensity of deep-water renewal between successive surveys. Schlosser et al. (1991) and Rhein (1991) used this method and the deep-water ventilation in the Greenland Sea has decreased since the 1980s compared to the earlier part of the record. Dickson (1997) links the cessation of convective bottom-water renewal to warmer than normal winter air temperatures during the last decade. These, in turn, are attributed to the prevailing positive phase of the North Atlantic Oscillation (NAO: e.g., Hurrell 1995; Rogers and van Loon 1979). During a positive NAO phase, an increased number of winter storms advect warmer than normal air masses into the Greenland Sea and reduce the number of cold air outbreaks from the Arctic. Consequently, the total winter heat loss is reduced and deep convection is less likely to occur.

The absence of deep convective bottom-water renewal has lead to a slow but steady warming of Greenland Sea bottom-water temperature (Fig. 2; updated from Bönisch et al. 1997; Clarke et al. 1990). This can be explained by one of two mixing pathways: lateral exchange with the warmer deep waters of the Norwegian 


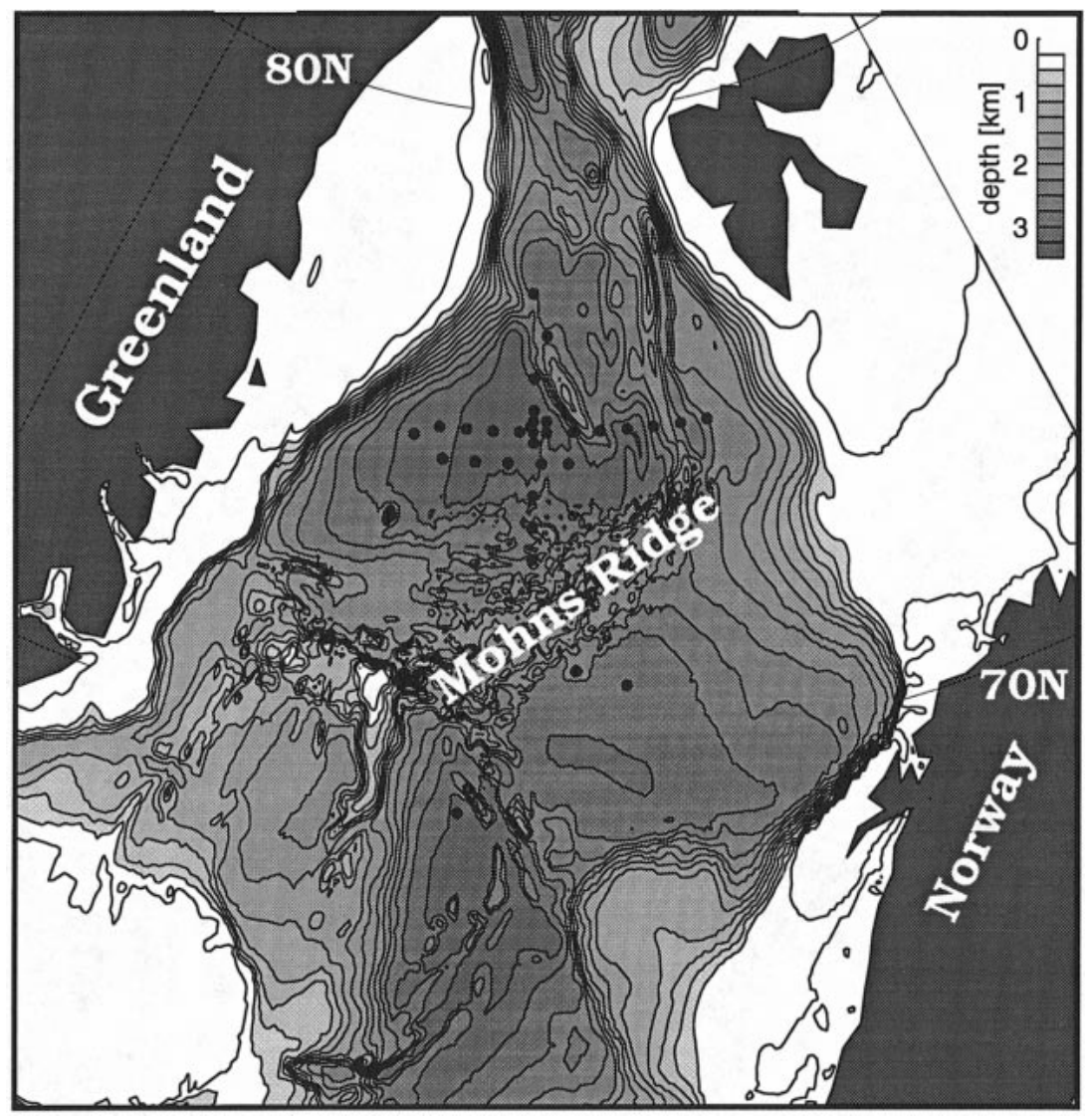

FIG. 1. Bathymetry of the Greenland Sea and position of the CTD stations from the 1997 survey. The deepest convection occurs in the center of Greenland Sea near $75^{\circ} \mathrm{N}, 3^{\circ}-5^{\circ} \mathrm{W}$.

Basin and/or the Arctic Ocean (e.g., Dickson et al. 1996) or vertical exchange with warmer intermediate waters (this study). Anthropogenic tracer like chloroflurocarbons (CFCs) exhibit a different regional distribution with high concentrations in the upper ocean and very low concentrations in the older deep waters (Fig. 3). They, therefore, provide an additional means to distinguish between the two proposed mixing pathways.

In the following we present the observational evidence and discuss several "ventilation" pathways in the absence of deep convective bottom water renewal.

\section{Observations}

The thermal stratification of the Greenland Sea can be described as a three-layer system (e.g., Carmack and Aagaard 1973): A surface layer that in winter is close to freezing temperature and characterized by low salinity and well enriched in CFCs; the intermediate layer below carries a mixture of waters of Atlantic and Arctic origin and is generally warmer and saltier compared to the surface and deeper waters (e.g., Fig. 4b); finally, the lowest layer, the Greenland Sea deep or bottom water, is one of the densest water masses in the world's oceans. It is believed to be ventilated by deep convective mixing during the late winter season. As the winter proceeds, the intermediate water is entrained into the very cold surface mixed layer, causing a significant warming of the surface waters despite strong surface cooling. Visbeck et al. (1995) give a detailed description of the seasonal upper-ocean temperature evolution and show that despite the warming due to entrainment of the intermediate water, the late winter mixed layer is still colder than the deep water. Thus, deep convection in the Greenland Sea is cooling (and freshening) the deep waters.

The temperature evolution of the deep Greenland Sea has been documented since the late 1950s with hydrographic stations every $2-10$ years (Fig. $2 b$ ). In recent years several efforts have been made to document the evolution of other deep-water properties. For example, the CFC concentration has been measured in the Greenland Sea Deep Water since 1982 (Bullister and Weiss 1983). The total amount of CFC in the Greenland Sea Deep Water (GSDW) was quite high in 1982 (Figs. 2a, 3 ), which can only be explained by an efficient, most likely deep convective, renewal process. The evolution of atmospheric CFC concentrations suggest that a few deep convective events preferentially in the later part of the 1970s are required to account for the observed 

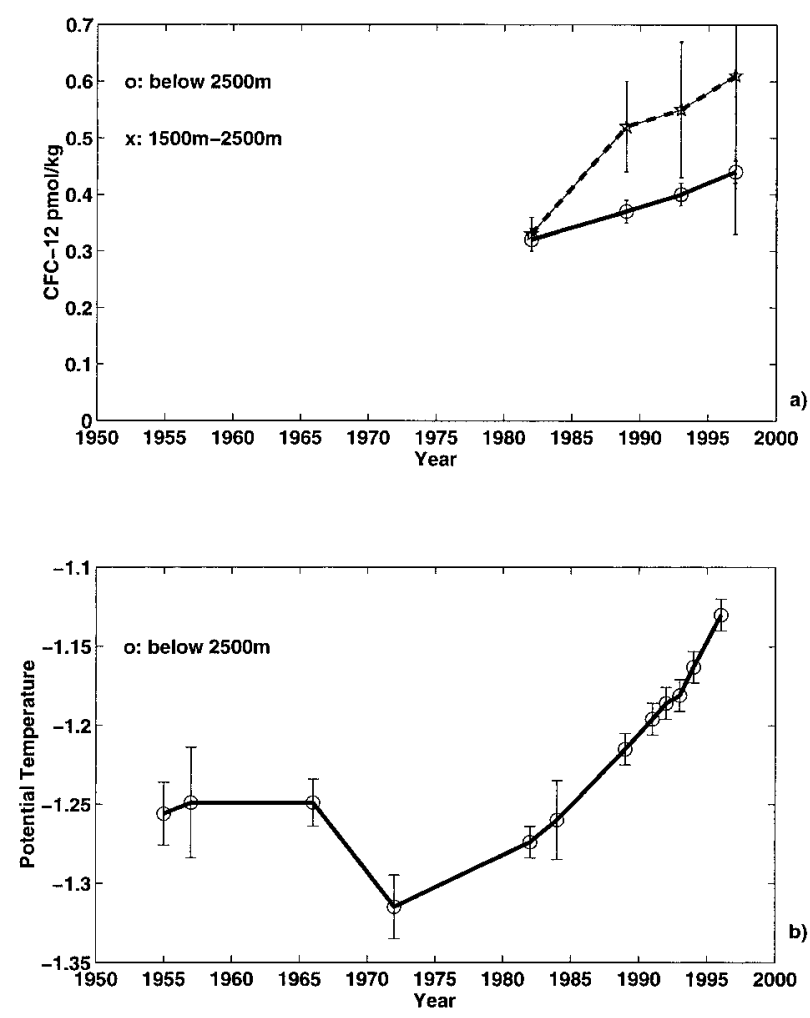

FIG. 2. Time series of deep-water properties for the central Greenland Sea. (a) Depth-averaged CFC concentrations for depth greater than $2500 \mathrm{~m}$ (circles and solid line) and for the layer between 1500 and $2500 \mathrm{~m}$ (stars and dashed line). The error bars give the standard deviation over the typically $4-10$ hydrographic stations. (b) Depth averaged potential temperature updated from Bönisch et al. (1997).

CFC concentrations in the deep water (Bönisch and Schlosser 1995). However, the GSDW tracer concentration increase between 1982 and 1989 was small and indicates a much reduced ventilation (Rhein 1991; Schlosser et al. 1991). The situation has not changed much recently. However, extensive surveys during the summers of 1993 and 1997 demonstrated that deep CFC concentrations are increasing further, and the signal is greater than the attributable uncertainties in the intercruise calibration (Fig. 2a) (see also Bönisch et al. 1997). The increase is steady, deep reaching, and occurs during a period when deep convection is unlikely, as inferred from the extensive CTD dataset (e.g. Bönisch et al. 1997; Budeus et al. 1998) or ongoing mooring work (F. Schott and J. Meincke 1997, personal communication).

In the following we discuss which mechanisms might have caused the deep CFC-12 concentration increase.

\section{Nonconvective "ventilation" scenarios}

A regime dominated by horizontal/isopycnal exchange with the surrounding less well ventilated deep waters, low in CFCs, would decrease the CFC concentration with time (Rhein 1996; Swift and Koltermann

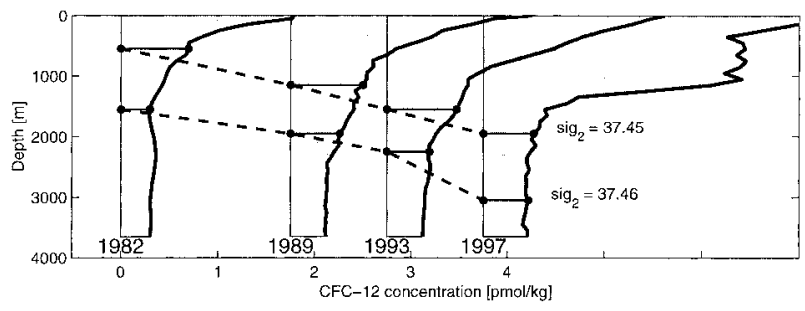

FIG. 3. Time evolution of CFC-12 concentration profiles. The concentration profiles (thick solid line) are offset by $0.25 \mathrm{pmol} / \mathrm{kg}$ per year. Zero concentration (thin vertical lines) and the year of the survey are included. Additionally the depth evolution of two isopycnal surfaces $\left(\sigma_{2}=37.34\right.$ and 37.46$)$ is represented by dashed lines.

1988). High CFCs are abundant in shallower layers and significant downward/diapycnal transfer between these shallower layer and the deeper water would be able to explain the observations.

A more systematic approach would be to analyze the tracer tendency equation:

$$
\frac{\partial \tau}{\partial t}=-\mathbf{u} \cdot \nabla_{H} \tau-w \frac{\partial \tau}{\partial z}+k_{H} \nabla_{H}^{2} \tau+k_{v} \frac{\partial^{2} \tau}{\partial z^{2}}+S,
$$

which in the absence of internal sources or sinks $(S)$ depends on four processes: horizontal and vertical advection and horizontal (isopycnal) and vertical (diapycnal) mixing. First we will diagnose the sign of each term. In the deep Greenland Sea horizontal diffusion $\left(k_{H} \nabla_{H}^{2} \tau\right)$ and horizontal advection $\left(\mathbf{u} \cdot \boldsymbol{\nabla}_{H} \tau\right)$ will both decrease the anthropogenic tracer concentration $(\tau)$ and would not contribute to the observed increase.

During years of active deep convection we expect a sporadic but extremely efficient vertical tracer transfer. In this framework one can think of the convective process as a large vertical mixing coefficient operating for only a short time in the center of the Greenland Sea. In the absence of deep convection, however, some ventilation might occur through less efficient but steady diffusive or advective processes.

One can evaluate the magnitude of the required vertical fluxes using a simplified one-dimensional tracer budget equation, which we can think of being representative of the interior of the Greenland Sea. We will retain only two processes, vertical advection and vertical diffusion:

$$
\frac{\partial \tau_{\text {deep }}}{\partial t}=\frac{\partial}{\partial z}\left(k_{v} \frac{\partial \tau}{\partial z}\right)-w \frac{\partial \tau}{\partial z}(+S) .
$$

Note that mass will be conserved by an appropriate lateral outflow $(u)$ and equivalent vertical motion within the periphery of the Greenland Sea, possibly within the bottom boundary layer. We proceed by discretizing the linearized terms and arrive at

$$
\frac{\Delta \tau_{t}}{\Delta \tau_{z}} \sim\left(\frac{k_{v}}{H}-w\right)
$$

where $k_{v}$ and $w$ represent the vertical mixing rate and 

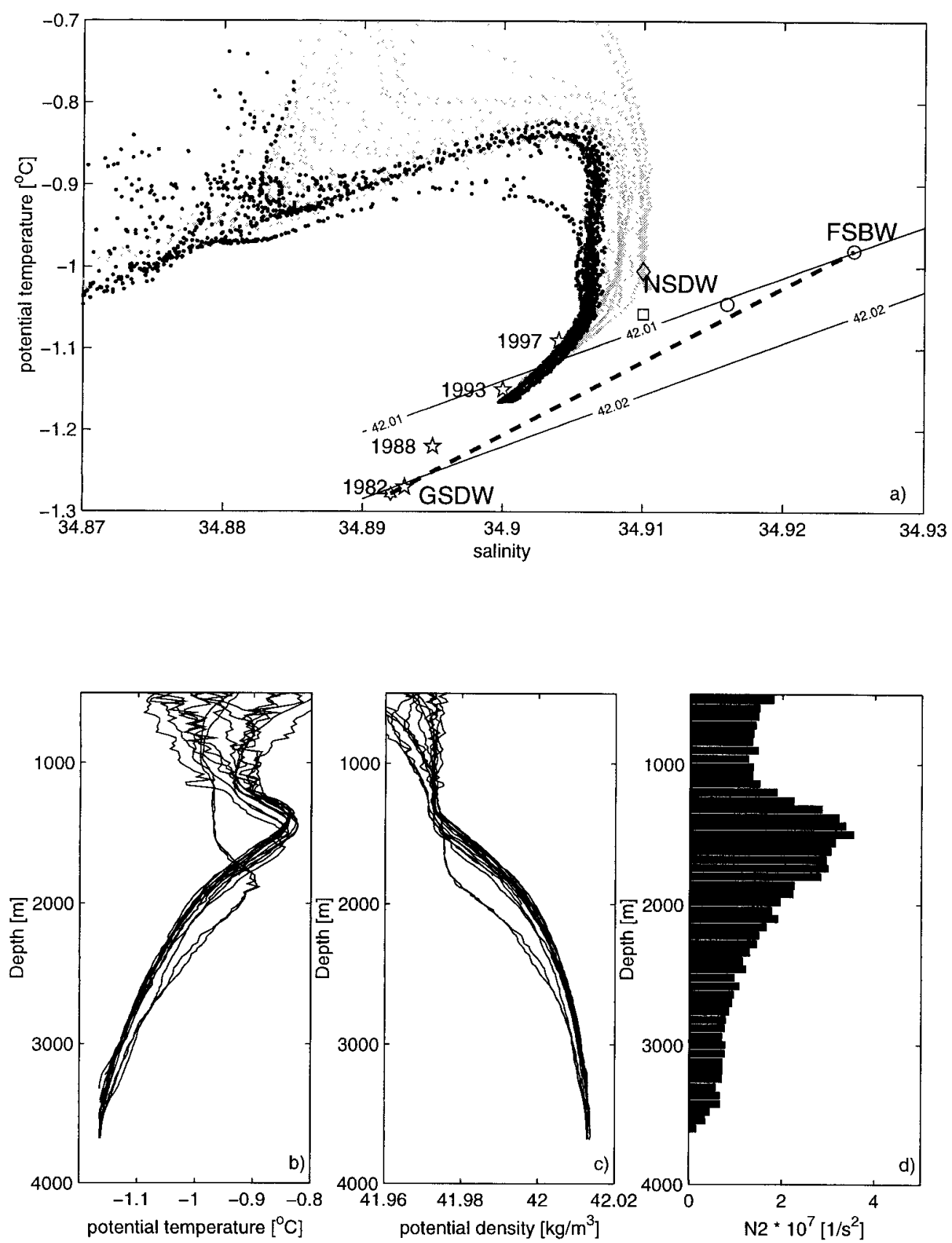

FIG. 4. Hydrographic properties of the Greenland Sea below 500-m depth as observed during the 1997 survey. (a) Potential temperature versus salinity diagram for all stations of the 1997 survey (Fig. 1). The stations within the Greenland Sea are shown as dark points, the others in gray. Two deep isopycnals referenced to 3000 dbar are represented by the thin solid lines. Several bottom water properties from the deep water survey during 1982 (Clarke et al. 1990) are included. The two open circles represent bottom waters within Fram Strait (FSBW); a diamond: Norwegian Sea Deep Water (NSDW), the square: Boreas Basin; and the smaller star: Greenland Sea Deep Water (GSDW). The thick dashed line is an ideal mixing line between the FSBW and GSDW. Finally, four larger stars represent the time evolution of GSDW properties averaged from $2000 \mathrm{~m}$ to the bottom. The year of each survey is indicated. (b) Potential temperatures for all station within the Greenland Sea from the 1997 survey. (c) Same as (b) but for potential density referenced to 3000 dbar. (d) Median stability $N^{2}=-(g /$ $\left.\rho_{0}\right) \partial \sigma / \partial z$ of the stations shown in (c) 
TABLE 1. Tracer tendency, gradient, and implied vertical transfer rates. The tendency $\left(\Delta \tau_{t} \cdot \Delta t\right)$ is given as the tracer difference between two surveys 15 years apart (1982-97). The vertical gradient $\left(\Delta \tau_{z} \cdot \Delta z\right)$ is given as the difference between 1500- and 2500-m depth. The ratio $\Delta \tau_{t} / \Delta \tau_{z}$ yields the required downwelling rate or vertical diffusivity $\left(k_{v, \text { av }} / H-w\right)$ using $H=\Delta z=1000 \mathrm{~m}$ and $\Delta t=15 \mathrm{yr}$.

\begin{tabular}{lcccc}
\hline \hline Tracer $\tau$ & Units & $\Delta \tau_{t} \cdot \Delta t$ & $\Delta \tau_{z} \cdot \Delta z$ & $k_{v, \text { av }} / H-w$ \\
\hline Temperature & ${ }^{\circ} \mathrm{C}$ & 0.14 & 0.7 & $2 \times 10^{-6}$ \\
Salinity & & 0.01 & 0.05 & $2 \times 10^{-6}$ \\
CFC-12 & $\mathrm{pmol} \mathrm{kg}^{-1}$ & 0.1 & 0.3 & $3 \times 10^{-6}$ \\
\hline
\end{tabular}

vertical advection across a layer at $2000 \mathrm{~m}$ depth and $H$ denotes the thickness of the lower layer $(\sim 1000 \mathrm{~m})$.

We then use the hydrographic observations to evaluate the left-hand side of Eq. (3). For example Fig. 2 gives the deep temperature and CFC tendency $\Delta \tau_{t}$ while the salinity evolution was taken from the dataset compiled by Bönisch et al. (1997) with the data from 1997 added (see also Fig. 4a). The vertical tracer gradients $\Delta \tau_{z}$ were estimated from climatological data.

Their values and ratio are summarized in Table 1 and give a consistent flux for all three tracers, for either an average downward velocity of $w \sim 2-3\left(\times 10^{-6} \mathrm{~m} \mathrm{~s}^{-1}\right)$ or a vertical diffusivity of $k_{v \text { av }} \sim 2-3\left(\times 10^{-3} \mathrm{~m}^{2} \mathrm{~s}^{-1}\right)$.

The sinking motion is equivalent to an downward interface displacement of 60-90 $\mathrm{m} \mathrm{yr}^{-1}$, which when multiplied with the area of the deep Greenland Sea basin $\left(\sim 200^{2} \mathrm{~km}^{2}\right)$ gives a downward volume transport of about $0.1 \mathrm{~Sv}\left(\mathrm{~Sv} \equiv 10^{6} \mathrm{~m}^{3} \mathrm{~s}^{-1}\right)$, consistent with the estimate by Bönisch et al. (1997). Inspection of the time evolution of two deep isopycnal surfaces $\left(\sigma_{2}=37.45\right.$ and 37.46) shows vertical displacements of similar magnitudes (Fig. 3a). Does this mean that a slow downward motion is ventilating the deep Greenland Sea during the absence of deep convection?

The inferred vertical diffusivity is a least a factor of 10 larger than the anticipated globally averaged values (e.g., Munk 1966) and two orders of magnitude larger than the observed diapycnal mixing rates in the thermocline (e.g., Ledwell et al. 1993). Is it reasonable for such large diapycnal mixing to occur in the deep Greenland Sea?

In the following we will discuss adiabatic (advective) and diabatic (diffusive) mechanisms that could contribute to a slow ventilation of the GSDW.

\section{a. Adiabatic ventilation processes}

Dickson et al. (1996) have proposed that the deep tracer concentration increase and warming might be the consequence of a collapsing dome. They argue that reduced convection, together with a weaker wind stress curl, would reduce the cyclonic circulation of the gyre and cause isopycnals to relax toward a deeper level. Hence, they explain the rising temperatures and tracer concentrations through an adiabatic vertical advective process.
The average wind stress curl in the region of the Greenland Sea gyre is cyclonic (Jonsson 1991), which results in an upwelling interior motion due to a divergent surface Ekman transport. Hence, a steady decrease of the wind stress curl over the last two decades could cause a sinking of isopycnal surfaces. However, inspection of sea level pressure from the National Centers for Environmental Prediction-National Center for Atmospheric Research (NCEP-NCAR) Reanalysis between 1958 and 1998 showed large interannual variability with a mild trend toward lower annual mean pressures in the center of the Greenland Sea. This trend would strengthen the Ekman divergence and cause increased upward motion in the interior, which is contrary to the observations.

Downward motion could also be induced by the collapse of a previously existing dome. However this process should come to a halt once the isopycnal surfaces are horizontally oriented. Judging from hydrographic surveys during the summers of 1984, 1989, and 1990 (Bullister and Weiss 1983; Smethie et al. 1986) the isopycnals and isotherms respectively show no sign of a well-established dome below $1500 \mathrm{~m}$ depth, which could have continued to collapse.

We were not convinced that either of those adiabatic mechanisms is capable of increasing the deep tracer concentration and, hence, pursued diabatic ventilation scenarios.

\section{b. Diabatic ventilation}

There are principally two processes that contribute to the basin-averaged diapycnal mixing. First, in the interior of the ocean small-scale turbulence (i.e., internal wave breaking) causes diapycnal mixing [e.g., Gregg (1987) and references therein]. The associated diapycnal "pelagic" diffusivities in the deep ocean away from shelves and bottom boundary layers are about $k_{v} \sim 1-5$ $\left(\times 10^{-5} \mathrm{~m}^{2} \mathrm{~s}^{-1}\right)$ (see Munk and Wunsch (1998) for a recent review) and are much to small to explain the observations in the deep Greenland Sea.

Second, Munk (1966) and Armi (1978) pointed out that intense diapycnal mixing close to the boundaries within the bottom boundary layer coupled with horizontal mixing by mesoscale eddies can provide a significant contribution to the overall diapycnal mixing for a deep layer (see also Garrett 1991). The effective basinaverage diapycnal diffusivity $\left(k_{v \text {,av }}\right)$ for a layer depends on two parameters, the diffusivity within the boundary layer $\left(k_{v, \text { bbl }}\right)$ and the ratio between the total area $(A)$ of the layer to the area where enhanced mixing occurs $\left(A_{\mathrm{bbl}}\right)$ :

$$
k_{v, \mathrm{av}}=k_{v, \mathrm{bbl}} \frac{A_{\mathrm{bbl}}}{A} .
$$

The magnitudes of diapycnal diffusivities within bottom boundary layers are not well known, but Polzin et al. (1997) found rather large values of $k_{v, \text { bbl }} \sim 10-100$ 

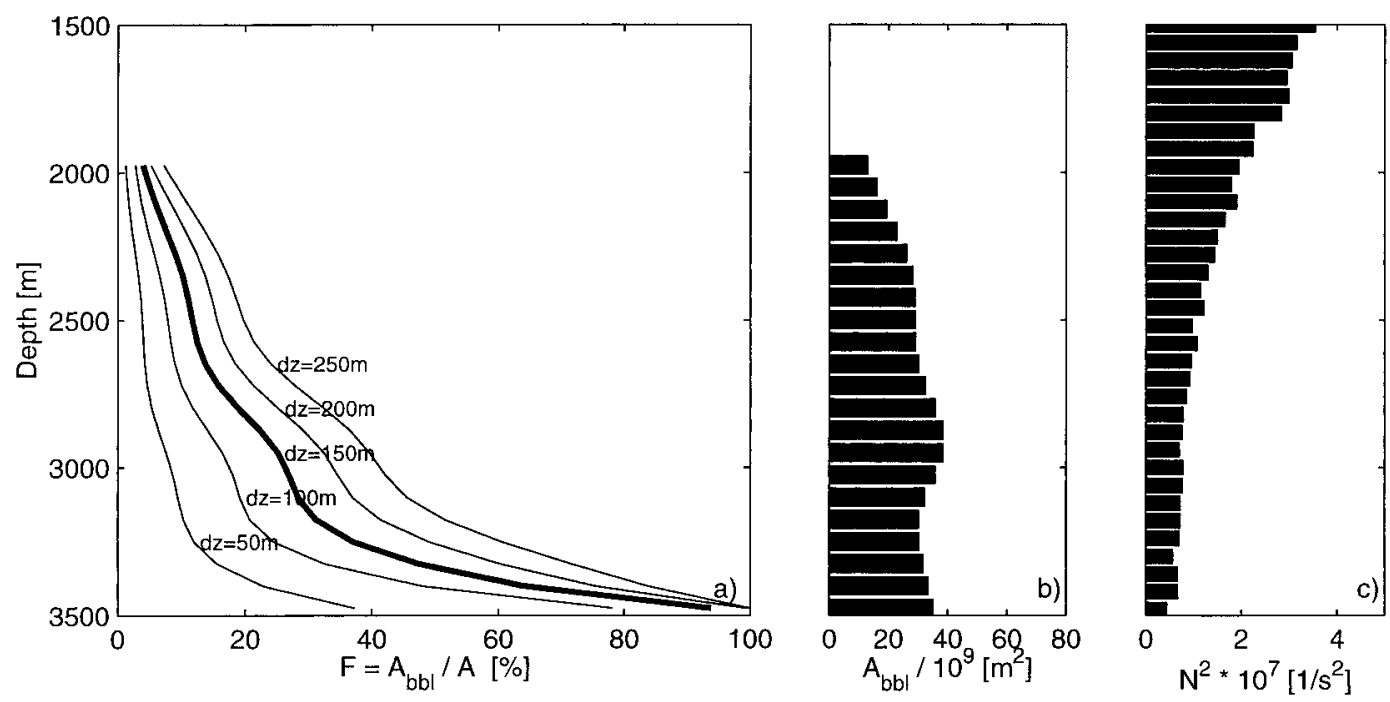

FIG. 5. (a) Statistical analysis of the bathymetry in the central Greenland Sea. The thick solid line shows the fraction of the total area as a function of depth, which would be within a bottom boundary layer of a thickness $d z=150 \mathrm{~m}$. Five values of $d z$ were chosen: 50,100,150,200, and $250 \mathrm{~m}$ and all calculation are based on the ETOPO5 bathymetric dataset. (b) Area $\left(A_{\mathrm{bbl}}\right)$ of a 150-m-thick boundary layer. (c) Stratification profile for the interior of the Greenland Sea (see also Fig. 4c).

$\left(\times 10^{-4} \mathrm{~m}^{2} \mathrm{~s}^{-1}\right)$ in the Brazil Basin over rough topography near the Mid-Atlantic Ridge.

The energy source is assumed to be largely tidal (Munk and Wunsch 1998), which can be transformed into a baroclinic velocity field by internal wave scattering in regions of large bottom slopes (e.g., Eriksen 1985; Gilbert and Garrett 1989; Toole et al. 1997). The semidiurnal tidal energy levels in the Brazil basin are similar to the Greenland Sea according to a global tidal model (LeProvost et al. 1994). This suggests that bottom-boundary-layer mixing rates over rough topography might be similar in both basins.

A more detailed inspection of the bathymetry of the deep Greenland Basin (Fig. 1) shows a complex ridge system (Mohns Ridge) to the southeast of the basin where rough topography can be expected. We have analyzed the ETOPO5 bathymetric data and computed $A_{\mathrm{bbl}} / A$ as the fraction of $10 \times 10 \mathrm{~km}^{2}$ grid cells whose depth is less than a fixed distance above the sea floor (Fig. 5a). For example, a layer centered at $3000 \mathrm{~m}$ depth has more than $25 \%$ of the total area within a $150-\mathrm{m}$ thick bottom boundary layer, while shallower surfaces show more typical values of $10 \%$.

The area within a 150 -m-thick boundary layer as a function of depth (Fig. 5b) is fairly constant below a depth of $2500 \mathrm{~m}$. The total area, however, is rapidly decreasing and, if one assumes that the diffusivity within the vicinity of the bottom boundary layer is spatially constant, one would expect increased area-averaged diapycnal mixing in the deeper part of the basin. This is consistent with the observed weak stratification below $2500 \mathrm{~m}$ depth (Fig. 5c).

Inspection of several hydrographic profiles from the area showed that bottom boundary mixed layers are typically 50-250 m thick (see also Budeus et al. 1998).

If most of the diapycnal mixing is happening in the vicinity of the bottom, one can use Eq. (4) and the overall tracer budget (Table 1) to estimate a boundarylayer diapycnal diffusivity. Assuming a 150-m-thick bottom boundary layer we arrive at a diffusivity of $k_{v, \text { bbl }}$ $\sim 10^{-2} \mathrm{~m}^{2} \mathrm{~s}^{-1}$, which is at the upper end of recently observed values elsewhere (Polzin et al. 1997). We conclude that diapycnal mixing within the bottom boundary mixed layer is a potent mechanism to slowly ventilate the GSDW in the absence of deep convection.

However, what are the dynamical implications of such large bottom boundary layer mixing?

\section{c. Boundary layer mixing driven secondary circulations}

Early research on mixing-induced circulation concentrated on alongslope flows produced in stratified flows in the presence of an inclined boundary (Phillips 1970; Wunsch 1970). Phillips (1970) derives the upslope transport [his Eq. (12)] to be $Q_{\text {upslope }}=k_{v} \cot (\alpha)$. For small slopes ( $\alpha$ is about 2 deg for a 3-km deep and 100$\mathrm{km}$ wide domain) this upward boundary-layer flux needs to be replenished by an interior downward motion. The implied total interior downward volume flux of this secondary circulation is

$$
M_{\text {down }}=C Q_{\text {upslope }}=k_{v} C \cot (\alpha),
$$

where $C$ denotes the circumference of the basin.

A few years later Thorpe (1987) considered a fully turbulent boundary-layer structure and has shown that 

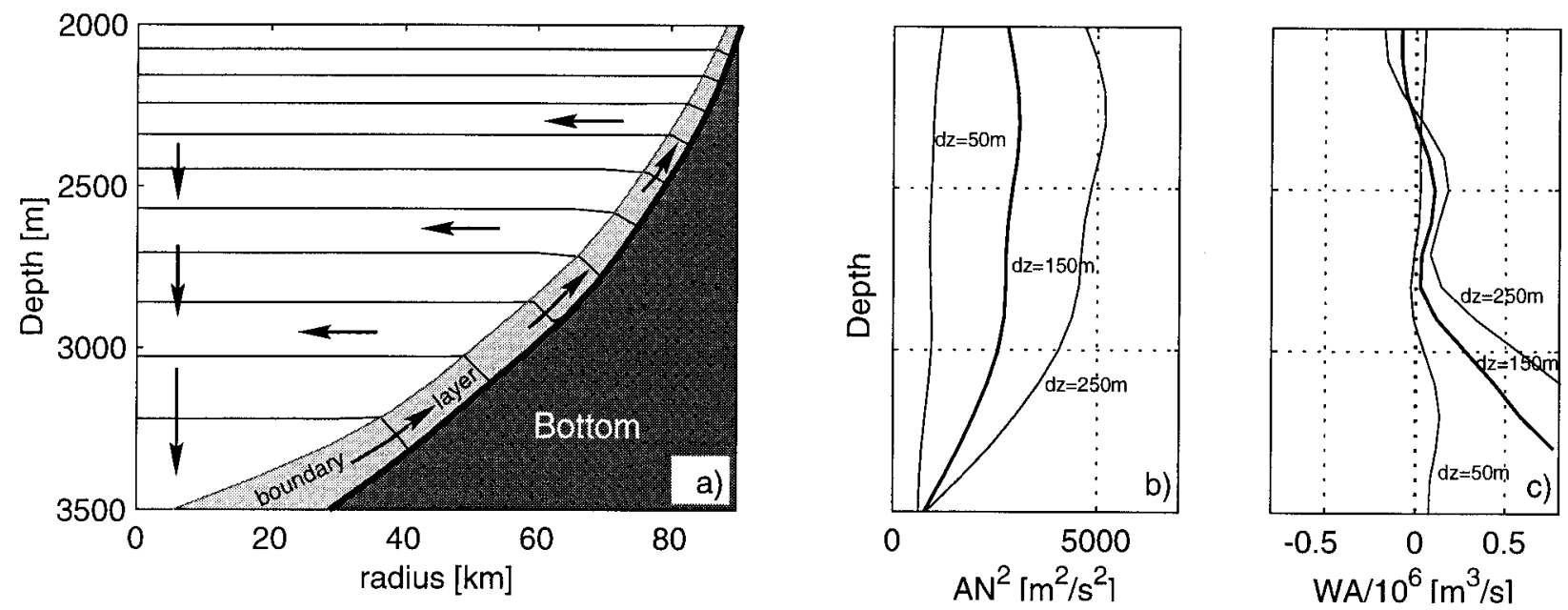

FIG. 6. (a) Idealized section through the deep Greenland Sea if its shape was circular (areas are preserved). The area of the bottom boundary layer for a height of $150 \mathrm{~m}$ is shaded. The thin solid line correspond to isopycnal surfaces given the mean $N^{2}$ profile (Fig. 4d). The arrows represent a boundary layer mixing-driven large-scale overturning circulation. (b) Profiles of the total area of the bottom boundary layer multiplied with $N^{2}$. (c) Profiles of implied vertical transport in the boundary layer (see text for details). All profiles have been calculated for three bottom boundary layer thicknesses $d z=50,150$, and $250 \mathrm{~m}$.

this process leads to a net motion along the slope proportional to the vertical diffusivity outside of the boundary layer. Finally, laboratory experiments by Phillips et al. (1986) with enhanced bottom boundary layer mixing in the presence of a vertically varying stratification demonstrated how the secondary circulation is linked to details of the stratification. In their two-layer experiment boundary layer mixing drives counter flowing velocities in the boundary layer with maximum convergence at the depth of maximum stratification. McDougall (1989) generalized those results and made a one-dimensional (vertical) buoyancy budget [similar to our Eq. (2), but restricted to the bottom boundary layer] to derive the net diapycnal transport

$$
A_{\mathrm{bbl}} w_{\mathrm{bbl}} N^{2}=\frac{\partial}{\partial z}\left(A_{\mathrm{bbl}} k_{v, \mathrm{bbl}} N^{2}\right)
$$

and its divergence $\left(u_{\text {outflow }}\right)$

$$
u_{\text {outflow }} C_{\mathrm{bbl}}=-\frac{\partial}{\partial z}\left(A_{\mathrm{bbl}} w_{\mathrm{bbl}}\right),
$$

where $A_{\mathrm{bbl}}$ denotes the total area of the bottom boundary layer, $C_{\mathrm{bbl}}$ its circumference, $w_{\mathrm{bbl}}$ the diapycnal velocity, $k_{v \text {,bbl }}$ the diapycnal mixing coefficient, and $N^{2}=$ $-\left(g / \rho_{0}\right) \partial \sigma / \partial z$ a measure of the vertical stratification.

Figures 6b,c show profiles of $\left(A_{\mathrm{bbl}} N^{2}\right)$ and the diapycnal volume transport $\left(A_{\mathrm{bbl}} w_{\mathrm{bbl}}\right)$ assuming a constant bottom boundary layer diffusivity of $\left(k_{v \text {,bbl }}=10^{-2} \mathrm{~m}^{2}\right.$ $\left.\mathrm{s}^{-1}\right)$. The vertical volume transport within the bottom boundary layer is of the order of $0.1-0.5 \mathrm{~Sv}$ and directed upslope below the maximum of $A_{\mathrm{bbl}} N^{2}$ at a depth of about 2000 to $2500 \mathrm{~m}$ (Fig. 6b). The implied lateral flow is directed out of the bottom boundary layer and is consistent with a basin-scale overturning circulation with interior downwelling below a depth of $2000 \mathrm{~m}$ (Fig.
6). Note, that details of this secondary circulation depend on the first and second derivative of the density profile, details of the bathymetry, and the assumption that we have made about the diapycnal diffusivity in the boundary layer.

This scenario suggests that enhanced boundary layer mixing may ventilate the deep Greenland Sea due to both diffusive and advective transports.

Let us consider a thought experiment where a tracer would be released in the deep Greenland Sea basin. In the interior vertical advection should dominate the tracer evolution while diapycnal mixing is largest in the boundary layer. Depending on the strength of the lateral exchange between the boundary layer and the interior one may or may not be able to observe a different tracer evolution in both regimes. A "back of the envelope" calculation allows us to compare the time it takes for a parcel in the interior to be vertically advected over a typical depth $H$ to the diffusive exchange time with the lateral boundary layer at a distance $L$. We will call their ratio $P$ :

$$
P=\frac{w L^{2}}{H k_{h}} .
$$

A ratio of $P=1$ means that both processes will be of similar importance. For the deep Greenland Sea $(H \sim$ $1000 \mathrm{~m}, L \sim 60 \mathrm{~km}$ and $w \sim 3 \times 10^{-6} \mathrm{~m} \mathrm{~s}^{-1}$ we arrive at a "critical" lateral diffusivity of $k_{h} \sim 30 \mathrm{~m}^{2} \mathrm{~s}^{-1}$. In the deep ocean we would expect much larger isopycnal diffusivity of order $k_{h} \sim 100-500 \mathrm{~m}^{2} \mathrm{~s}^{-1}$. Therefore one might not be able to distinguish the tracer evolution in the two regimes. This is consistent with the CFC observations, which show little gradients on isopycnal surfaces. 

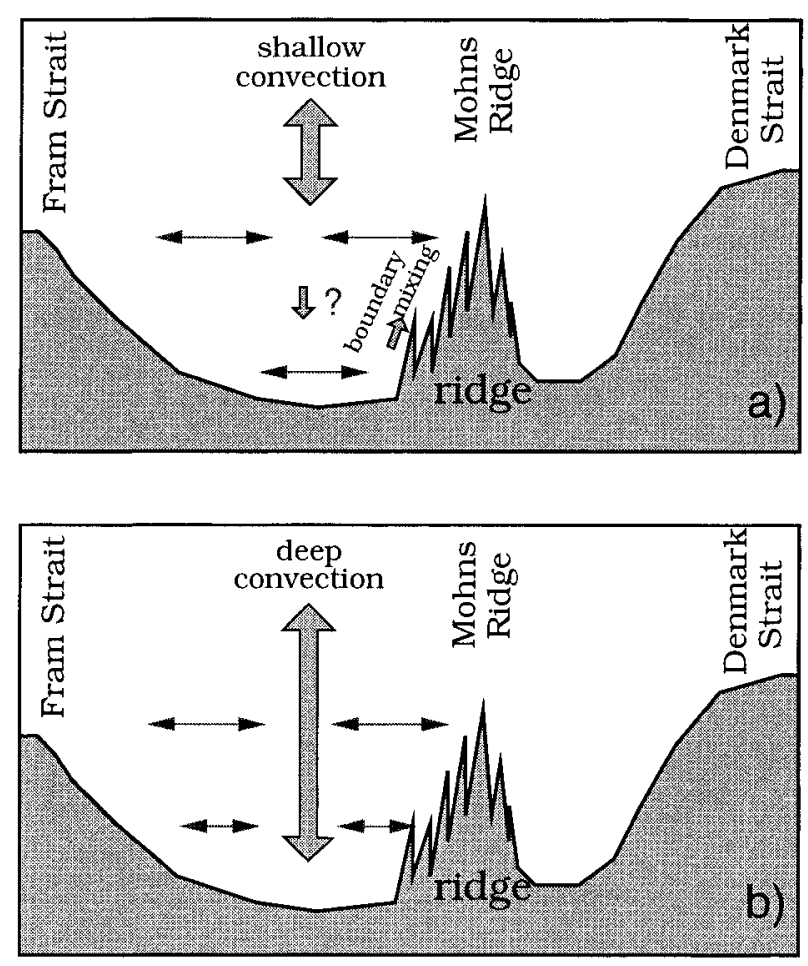

FIG. 7. Two ventilation scenarios for the deep Greenland Sea: (a) Shallow convection during a warmer climate ventilates the intermediate layers, eddies transfer the signal laterally, enhanced vertical mixing within the bottom boundary layer spreads the signal downward, and finally lateral stirring transfers the weakly ventilated water into the central deep basin. Boundary layer mixing might also result in a basin-scale overturning circulation with weak interior sinking. (b) Convective bottom water renewal during cold climates.

\section{Summary and conclusions}

During cold winter conditions the Greenland Sea bottom waters will most likely be renewed by deep convective mixing (Fig. 7b). Although deep convection has never been directly observed, the high concentrations of anthropogenic tracer in the bottom waters suggest that convective bottom-water renewal has occurred at least once during the late 1970s.

During milder winter conditions, however, we propose a more complicated, less efficient ventilation pathway (Fig. 7a): Late winter convection will mix surface waters down to intermediate depths of 1000-2000 m. Within the next several months lateral stirring along isopycnal surfaces will spread the newly formed water laterally throughout the basin. When this ventilated intermediate water encounters the bottom boundary layer or regions of rough topography, elevated levels of diapycnal mixing will transfer some fraction of the tracer signal to deeper layers. The better ventilated water will then mix from the boundary layer back into the interior by the same lateral stirring process. Enhanced boundarylayer mixing can also induce a secondary circulation with slow sinking in the interior contributing to the deep ventilation.
Several authors have suggested that much of the deep ocean diapycnal mixing might occur in the vicinity of the ocean floor within the bottom boundary layer (e.g., Armi 1978; Munk 1966; Munk and Wunsch 1998). Here we have followed up on these ideas and quantified how efficient this mixing process must be in order to explain the observed tracer evolution in the Greenland Sea Bottom Water.

We found that a basin-average diapycnal diffusivity of $k_{v \text {,av }} \sim 2 \times 10^{-3} \mathrm{~m}^{2} \mathrm{~s}^{-1}$ is needed to explain the deep tracer tendency. If this mixing is confined to a $150-\mathrm{m}-$ thick bottom boundary layer we arrive at a boundary layer diffusivity of $k_{v \text {,bbl }} \sim 10^{-2} \mathrm{~m}^{2} \mathrm{~s}^{-1}$. Recent observations from the Brazil basin over rough topography showed that such diffusivities are feasible (Polzin et al. 1997).

We have also shown that interior sinking and upslope motion in the bottom boundary layer can arise due to enhanced diapycnal mixing in the bottom boundary layer. For the deep Greenland Sea this mixing-driven overturning circulation may reach a strength of $0.1 \mathrm{~Sv}$.

In a recent paper Budeus et al. (1998) speculate about a steady downwelling throughout the water column. They suggest that Ekman transports in the bottom boundary layer might be responsible for the interior downwelling. Note that the Ekman transport in the bottom boundary layer is downslope for a cyclonic Greenland Sea gyre, implying upward interior motion. MacCready and Rhines (1993), however, argue that the net flow in the boundary layer might be upward due to secondary buoyancy forces. Our results indicate that a diapycnal mixing-driven overturning circulation cell can only exist below the maximum of $\left(N^{2} A_{\mathrm{bbl}}\right)$ at a depth of about $2000 \mathrm{~m}$ (Fig. 5).

A close inspection of the $T-S$ diagram (Fig. 4a) shows that the properties of Greenland Sea Deep Water, as represented by the stars, did not evolve along an isopycnal surface nor did they fall on a mixing line connecting Fram Strait bottom waters with the GSDW (dashed line). Their evolution followed a much steeper mixing line, consistent with significant diabatic exchange with intermediate waters.

It might be of interest to speculate about the evolution of Norwegian Sea Deep Water (NSDW) in the presence of large diapycnal mixing in the Greenland Sea. NSDW is believed to be formed by mixing Eurasian Basin deep water with overflows of GSDW through gaps in Mohns Ridge (Swift and Koltermann 1988). It is conceivable that more rapid diapycnal mixing in the smaller Greenland Basin would cause the horizontal density gradient across Mohns Ridge to change sign and hence reverse the overflow. Oesterhus et al. (1996) show observational evidence for such a flow reversal in some of the gaps near Jan Mayen between the 1980s and 1990s.

Diapycnal mixing also decreases the overall stratification of the deep water column (Fig. 4d), reducing the buoyancy barrier for future deep convective events. This interplay between deep convection, which injects dense 
water to the deep ocean, and a slow diffusive destratification has been shown to cause oscillatory behavior in simple models of the thermohaline circulation. The timescale of the oscillation is controlled by the diapycnal diffusivity [e.g., Winton and Sarachik (1993) and references therein]. Our findings suggest that, at least in some convection regions, the effective diffusivity might be more than an order of magnitude larger than the values used in their modeling study.

It seems worthwhile to try to observationally verify the anticipated large diapycnal mixing rates near the margins of the deep Greenland Sea. One could mount a field campaign to directly measure the diapycnal mixing near Mohns Ridge using microstructure-based dissipation measurements.

One might also be able to conduct a deliberate tracer release experiment near the rough topography in the deep water. During the first weeks one would expect the dye to spread mainly laterally with only weak diapycnal mixing. Its center of mass, however, might sink a few meters due to the boundary mixing-driven secondary circulation. Finally, after a few months when some of the dye has encountered the bottom boundary layer, a much larger overall diapycnal spreading should be found. In the near future it will not be feasible to utilize $\mathrm{SF}_{6}$ for such a deliberate tracer release experiment since it was already released at intermediate depth $(350 \mathrm{~m})$ in the Greenland Sea a few years ago (A. Watson and J. Ledwell 1998, personal communication).

Acknowledgments. We would like to thank two anonymous reviewers for constructive comments on earlier versions of the paper. MV acknowledges financial support for a six week long visit to Kiel by the Deutsche Forschungsgemeinschaft under SFB460 "Dynamik thermohaliner Zirkulationsschwankungen" and grants from Office of Naval Research under N00014-98-10302 and N00014-96-1-0573. The final version of the manuscript was prepared during a visit of MV at CSIRO, Hobart. MV is indebted to Trevor McDougall for his hospitality and stimulating discussions on bottom boundary layer mixing. Financial support for MR was given by the BMBF (ARKTIEF Project Grant 03F 0178 B). MR thanks the captain and crew of the RV Valdivia 166 cruise for technical support.

\section{REFERENCES}

Armi, L., 1978: Some evidence for boundary mixing in the deep ocean. J. Geophys. Res., 83, 1971-1979.

Bönisch, G., and P. Schlosser, 1995: Deep water formation and exchange rates in the Greenland/Norwegian Seas and the Eurasian Basins of the Arctic Ocean derived from tracer balances. Progress in Oceanography, Vol. 35, Pergamon, 29-52.

— J. Blindheim, J. Bullister, P. Schlosser, and D. Wallace, 1997: Long-term trends of temperature, salinity, density, and transient tracers in the central Greenland Sea. J. Geophys. Res., 102, $18553-18571$.

Budeus, G., W. Schneider, and G. Krause, 1998: Winter convective events and bottom water warming in the Greenland Sea. J. Geophys. Res., 103, 18 513-18 528.

Bullister, J., and R. Weiss, 1983: Anthropogenic chlorofluoromethanes in the Greenland and Norwegian Sea. Science, 221, 265268.

Carmack, E., and K. Aagaard, 1973: On the deep water of the Greenland Sea. Deep-Sea Res., 20, 687-715.

Clarke, R., J. Swift, J. Reid, and K. P. Koltermann, 1990: The formation of Greenland Sea Deep Water: Double diffusion or deep convection? Deep-Sea Res., 37, 1385-1424.

Dickson, B., 1997: From the Labrador Sea to global change. Nature, 386, 649-650.

Dickson, R., J. Lazier, J. Meincke, and P. Rhines, 1996: Long-term coordinated changes in the convective activity of the North Atlantic. Decadal Climate Variability, D. Anderson and J. Willebrand, Eds., Global Environmental Change, Springer, 211-261.

Eriksen, C., 1985: Implications of ocean bottom reflection for internal wave spectra and mixing. J. Phys. Oceanogr., 15, 1145-1156.

Garrett, C., 1991: Marginal mixing theories. Atmos-Ocean, 29, 313 339.

Gilbert, D., and C. Garrett, 1989: Implications for ocean mixing of internal wave scattering off irregular topography. J. Phys. Oceanogr., 19, 1716-1729.

Gregg, M., 1987: Diapycnal mixing in the thermocline: A review. $J$. Geophys. Res., 92, 5249-5289.

Hurrell, J., 1995: Decadal trends in the North-Atlantic OscillationRegional temperatures and precipitation. Science, 269, 676-679.

Jonsson, S., 1991: Seasonal and interannual variability of wind stress curl over the Nordic Seas. J. Geophys. Res., 96, 2649-2659.

Ledwell, J., A. Watson, and C. Law, 1993: Evidence for slow mixing across the pycnocline from an open-ocean tracer-release experiment. Nature, 364, 701-703.

LeProvost, C., M. Genco, F. Lyard, P. Vincent, and P. Canceil, 1994: Spectroscopy of the world ocean tides from a finite element hydrodynamic model. J. Geophys. Res., 99, 24 777-24 797.

MacCready, P., and P. B. Rhines, 1993: Slippery bottom boundary layers on a slope. J. Phys. Oceanogr., 23, 5-22.

McDougall, T., 1989: Dianeutral advection. Proc. Fifth 'Aha Huliko'a Hawaiian Winter Workshop on Parameteriation of Small-Scale Process, Honolulu, HI, Hawaii Institute for Geophysics, 289315.

Munk, W., 1966: Abyssal recipes. Deep-Sea Res., 13, 207-230.

—, and C. Wunsch, 1998: Abyssal recipes ii: Energetics of tidal and wind mixing. Deep-Sea Res., 45, 1977-2010.

Oesterhus, S., W. Turrell, B. Hansen, J. Blindheim, and A. V. Bennekom, 1996: Changes in the Norwegian seas deep water. ICES $C M, O, 11$.

Peterson, W., and C. Rooth, 1976: Formation and exchange of deep water in the Greenland and Norwegian Seas. Deep-Sea Res., 23, 273-283.

Phillips, O., J.-H. Shyu, and H. Salmun, 1986: An experiment on boundary mixing: Mean circulation and transport rates. J. Fluid. Mech., 173, 473-499.

Phillips, O. M., 1970: On flows induced by diffusion in a stably stratified fluid. Deep-Sea Res, 17, 435-443.

Polzin, K. L., J. M. Toole, J. R. Ledwell, and R. W. Schmitt, 1997: Spatial variability of turbulent mixing in the abyssal ocean. Science, 276, 93-96.

Rhein, M., 1991: Ventilation rates of the Greenland and Norwegian Seas derived from distributions of the chlorofluoromethanes F11 and F12. Deep-Sea Res., 38, 485-503.

— 1996: Convection in the Greenland Sea, 1982-1993. J. Geophys. Res., 101, 18 183-18 192.

Rogers, J. C., and H. van Loon, 1979: The seesaw in winter temperatures between Greenland and northern Europe. Part II: Some oceanic and atmospheric effects in middle and high latitudes. Mon. Wea. Rev., 107, 509-519.

Rudels, B., D. Quadfasel, H. Friedrich, and M.-N. Houssais, 1989: Greenland Sea convection in the winter of 1987-1988. J. Geophys. Res., 94, 3223-3227. 
Schlosser, P., G. Bönisch, M. Rhein, and R. Bayer, 1991: Reduction of deepwater formation in the Greenland Sea during the 1980s: Evidence from tracer data. Science, 251, 1054-1056.

Schott, F., M. Visbeck, and J. Fischer, 1993: Observations of vertical currents and convection in the central Greenland Sea during the winter of 1988/89. J. Geophys. Res., 98, 14 401-14 421.

Smethie, W., Jr., H. Östlund, and H. Loosli, 1986: Ventilation of the deep Greenland and Norwegian Seas: Evidence from krypton85, tritium, carbon 14 and argon-39. Deep-Sea Res., 33, 675703.

Swift, J., and K. Koltermann, 1988: The origin of Norwegian Sea Deep Water. J. Geophys. Res., 93, 3563-3569.
Thorpe, S., 1987: Current and temperature variability on the continental slope. Philos. Trans. Roy. Soc. London, 323, 471-517.

Toole, J., R. Schmitt, K. Polzin, and E. Kunze, 1997: Near-boundary mixing above the flanks of a midlatitude seamount. J. Geophys. Res., 102, 947-959.

Visbeck, M., J. Fischer, and F. Schott, 1995: Preconditioning the greenland sea for deep convection: Ice formation and ice drift. J. Geophys. Res., 100, 18 484-18 502.

Winton, M., and E. Sarachik, 1993: Thermohaline oscillations induced by strong steady salinity forcing of ocean general circulation models. J. Phys. Oceanogr., 23, 1389-1410.

Wunsch, C., 1970: On oceanic boundary mixing. Deep-Sea Res., 17, 293-301. 